\title{
T313M polymorphism of the PINK1 gene in Parkinson's disease
}

\author{
QIN LUO $^{1 *}$, XINLING YANG ${ }^{1 *}$, YANI YAO $^{1}$, HONGJUAN LI $^{2}$ and YULING WANG ${ }^{1}$ \\ ${ }^{1}$ Department of VIP Integrated Medicine, The First Affiliated Hospital of Xinjiang Medical University, Urumqi, \\ Xinjiang 830054; ${ }^{2}$ Department of Rehabilitation, The People's Hospital of Wenling, \\ Wenling, Zhejiang 317500, P.R. China
}

Received November 30, 2013; Accepted March 31, 2014

DOI: 10.3892/etm.2014.1702

\begin{abstract}
The present study aimed to investigate the association between T313M polymorphism at exon 4 of the PTEN-induced putative kinase 1 (PINK1) gene and Parkinson's disease (PD) in the Uygur and Han populations of Xinjiang, China. Genetic DNA was extracted from 364 patients with PD from the Uygur and Han populations, as well as 346 normal control patients. Four exons of the PINK1 gene were amplified using quantitative polymerase chain reaction. The exons were then digested for restriction fragment length polymorphism analysis. Gene types and allele frequencies were identified using agarose gel electrophoresis followed by DNA sequencing to analyze the T313M polymorphisms. In the Han population, T313M polymorphism allele frequency was observed to be significantly different between the PD group and the control group $\left(\chi^{2}=6.247 ; \mathrm{P}<0.05\right)$. Significant differences were observed in in the T313M allele and genotype frequencies between the Uygur and Han populations $\left(\chi^{2}=5.475\right.$ and $\chi^{2}=10.950$, respectively; $P<0.05)$. Polymorphisms in the PINK1 T313M mutation may be associated with genetic susceptibility to PD.
\end{abstract}

\section{Introduction}

Parkinson's disease (PD) is a common neurodegenerative disease that is prevalent in $1-2 \%$ of individuals aged $\geq 65$ years. While the specific etiology of PD is yet to be elucidated, genes involved in the development of the disease have attracted much research attention. At present, three autosomal recessive genes have been identified to be associated with PD, including PTEN-induced putative kinase 1 (PINK1), parkin, and DJ-1 (1-3). The PINK1 gene encodes a cytosolic E3 ubiquitin

Correspondence to: Professor Xinling Yang, Department of VIP Integrated Medicine, The First Affiliated Hospital of Xinjiang Medical University, 789 Suzhou Road, Urumqi, Xinjiang 830054, P.R. China

E-mail: xlyndoc@163.com

*Contributed equally

Key words: Uygur nationality, Han nationality, Parkinson's disease, PINK1 gene, polymorphism ligase and a mitochondrial serine/threonine kinase. PINK1 mutations were initially observed in consanguineous families of Italian and Spanish origin and are associated with slowly progressive PD with an onset prior to 50 years of age $(4,5)$. PINK1 mutations have been reported in Filipino, Taiwanese, Israeli, Japanese, Irish and North American populations, and also in Chinese populations (6-11).

In order to investigate PINK1 mutations in PD and analyze the distribution of PINK1 gene T313M polymorphisms in the Uygur and Han populations of China, patients with PD and healthy individuals were investigated. The significance of PINK1 T313M polymorphisms in the pathogenesis of PD was also assessed.

\section{Materials and methods}

Diagnostic criteria. The present study was performed in accordance with British Brain Bank diagnostic criteria (12), with partial diagnoses and complex cases confirmed by a senior doctor from the Neurological Department of the First Affiliated Hospital of Xinjiang Medical University (Urumqi, China). Over the past 50 years, diagnostic criteria for early onset and late onset PD have been defined by developments in head magnetic resonance imaging and computed tomography examinations. The present study excluded patients with secondary PD, Parkinson-plus syndromes, nervous system disease, hyperthyroidism and other genetic diseases. The present study was conducted in accordance with the Declaration of Helsinki and was conducted with approval from the Ethics Committee of the first Affiliated Hospital of Xinjiang Medical University. Written informed consent was obtained from all participants.

Patient data. In the present study, 364 patients with PD from the Uygur and Han populations of Xinjiang, China were selected between July 2010 and March 2011 as the case group. These patients included 175 individuals from the Uygur population, of which 99 were male and 76 were female, aged between 31 and 95 years (mean, 62.63 12.71 years). The remaining 189 patients with $\mathrm{PD}$ were from the Han population, of which 107 were male and 82 were female, aged between 25 and 85 years (mean, 61.76 \pm 12.31 years). The control group comprised 346 healthy individuals without PD. These included 163 individuals from the Uygur population, of which 92 were male and 71 were female, aged between 33 and 90 years 
(mean, 62.78 \pm 12.50 years), and 183 individuals from the Han population, of which 101 were male and 82 were female, aged between 27 and 86 years (mean, 61.43 \pm 12.51 years). No significant differences in age or gender were observed between the individuals in the PD group compared with those in the control group $\left(\chi_{\text {gender }}^{2}=0.048, \mathrm{P}>0.05 ; \mathrm{t}_{\mathrm{age}}=1.445, \mathrm{P}>0.05\right)$.

DNA extraction. Subsequent to obtaining informed consent, $2 \mathrm{ml}$ venous blood was extracted from each patient. EDTA was used as an anti-coagulant and a blood extraction kit (Tiangen Biotech Co., Ltd., Beijing, China) was used to extract the DNA.

Primers. Primer3 software was used to design the primer sequences required for polymerase chain reaction (PCR) analysis. The primer sequences for exon 4 of the PINK 1 gene were as follows: 5'-GAATGTCAGTGC CAGTGTTGG-3' (forward) and 5'-AGATATGTTCCCTTT GCATGGC-3' (reverse). The length of amplified fragment was $429 \mathrm{bp}$ and the primers were synthesized by Huada Gene Company (Beijing, China).

Restriction fragment length polymorphism analysis. Restriction fragment length polymorphism analysis was performed using the $H g a I$ endonuclease (New England Biolabs, Inc., Ipswich, MA, USA) in a restriction enzyme reaction system with a total reaction volume of $20 \mu \mathrm{l}$. The reaction consisted of $10 \mu \mathrm{l}$ PCR product, $2 \mu \mathrm{l}$ NEBuffer $1.1(\mathrm{pH}=8.0), 7.7 \mu \mathrm{l}$ deionized double-distilled water and $0.3 \mu \mathrm{l} \mathrm{HgaI}$, at $37^{\circ} \mathrm{C}$ overnight.

Digested products confirmation. Digested products were subjected to agarose gel electrophoresis and the enzymes were analyzed using UV gel electrophoresis. In brief, the gene amplified by PCR was a 429-bp sequence of the fourth exon of the PINK1 gene fragment, which contained a HgaI enzyme restriction site. Upon $\mathrm{HgaI}$ restriction digestion, homozygous wild-type sequences were digested into two fragments of 265 bp and $164 \mathrm{bp}$. This genotype was type C/C. At the 938 site, a $\mathrm{C}$ to $\mathrm{T}$ mutation occurs, resulting in loss of the $\mathrm{HgaI}$ restriction site. Thus, mutant homozygote genotypes are not digested and remain as $429 \mathrm{bp}$ fragments, type T/T. Upon $\mathrm{HgaI}$ restriction digestion, heterozygous sequences are digested into fragments of 429, 265 and $164 \mathrm{bp}$. This heterozygous genotype is type $\mathrm{C} / \mathrm{T}$ (Fig. 1). The mutant genotype was sequenced which confirmed that the digestion results were accurate (Fig. 2).

Statistical analysis. Genotypes and allele frequencies were calculated using a direct counting method. Genotype data were subjected to Hardy-Weinberg equilibrium tests and alleles and genotypes were compared using the $\chi^{2}$ test. The constituent ratio of each group was analyzed using the $\chi^{2}$ test. All statistical analyses were performed using SPSS software, version 17.0 (SPSS, Inc., Chicago, IL, USA).

\section{Results}

Hardy-Weinberg equilibrium test. To show that the PINK1 genotype frequencies were equal in the case and control groups, the genotype frequencies of the case and control

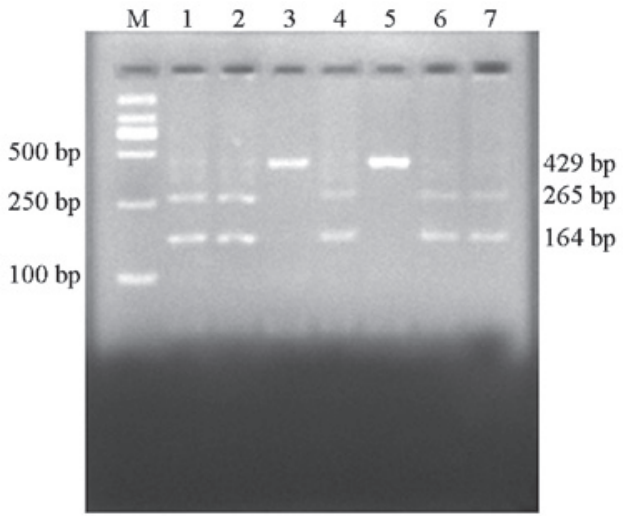

Figure 1. Genotypes of the PINK1 gene T313M polymorphism. Lanes 3 and 5 show homozygous mutant sequences which cannot be digested and remain as 429 bp fragments; type T/T. Lanes 1,2,4,6 and 7 show wild-type homozygous sequences that were digested into three fragments of 429, 265 and $164 \mathrm{bp}$; type C/T. M, 2,000 bp marker; PINK1, PTEN-induced putative kinase 1 .

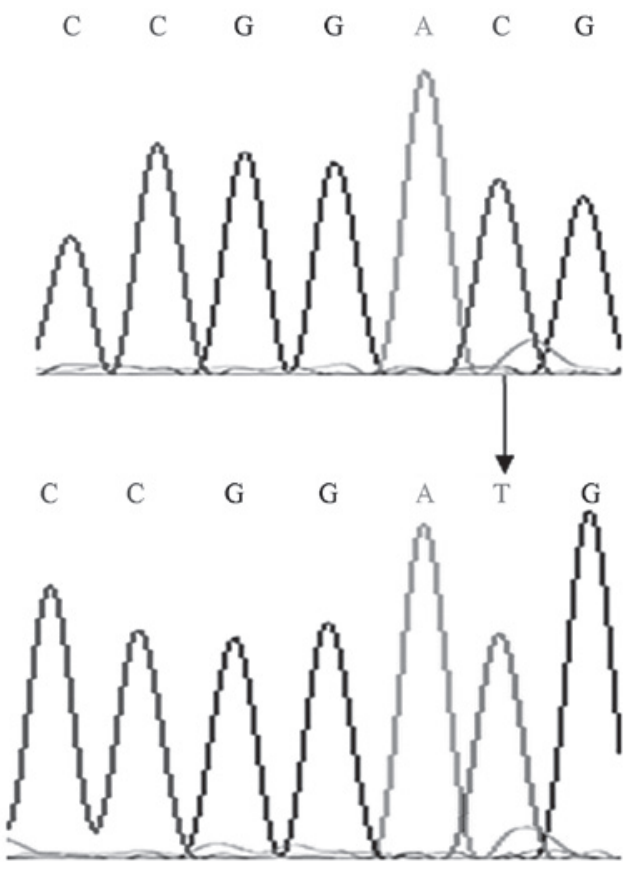

Figure 2. Sequencing of the fourth exon of the PINK1 gene in Parkinson's disease shows a mutation from $\mathrm{C}$ to $\mathrm{T}$ at the 938 site. The sequence around the mutation site is shown, with the arrow pointing to the substitution. PINK1, PTEN-induced putative kinase 1 .

groups were assessed using alignment inspection. The PINK1 genotype distributions in the case and control groups were in Hardy-Weinberg equilibrium and exhibited good consistency $(\mathrm{P}>0.05)$

T313M allele frequency distribution. Differences in polymorphic T313M alleles and genotype frequencies in the PD group compared with the control group were not observed to be statistically significant $(\mathrm{P}>0.05$; Table I). Furthermore, in the Uygur population, the genotype and allele frequencies in the PD group were not observed to be significantly different from those in the control group $(\mathrm{P}>0.05)$. Moreover, in the Han population, the genotype frequencies of the PD group showed no significant 
Table I. Allele and genotype frequencies of the PINK1 gene T313M polymorphism in patients with PD and healthy control individuals.

\begin{tabular}{|c|c|c|c|c|c|c|}
\hline \multirow[b]{2}{*}{ Groups } & \multirow[b]{2}{*}{ No. of cases } & \multicolumn{3}{|c|}{ Genotype frequency } & \multicolumn{2}{|c|}{ Allele frequency } \\
\hline & & $\mathrm{T} / \mathrm{T}, \mathrm{n}(\%)$ & $\mathrm{C} / \mathrm{T}, \mathrm{n}(\%)$ & $\mathrm{C} / \mathrm{C}, \mathrm{n}(\%)$ & T type, n (\%) & C type, n (\%) \\
\hline PD & 364 & $5(1.4)$ & $0(0.0)$ & 359 (98.6) & $10(1.4)$ & 718 (98.6) \\
\hline Control & 346 & $5(1.4)$ & $0(0.0)$ & $341(98.6)$ & $10(1.4)$ & $682(98.6)$ \\
\hline
\end{tabular}

PD, Parkinson's disease; PINK1, PTEN-induced putative kinase 1.

Table II. Allele and genotype frequencies of the PINK1 gene T313M polymorphism in patients with PD from Uygur and Han populations compared with healthy control individuals.

\begin{tabular}{|c|c|c|c|c|c|c|}
\hline \multirow[b]{2}{*}{ Groups } & \multirow[b]{2}{*}{ No. of cases } & \multicolumn{3}{|c|}{ Genotype frequency } & \multicolumn{2}{|c|}{ Allele frequency } \\
\hline & & $\mathrm{T} / \mathrm{T}, \mathrm{n}(\%)$ & $\mathrm{C} / \mathrm{T}, \mathrm{n}(\%)$ & $\mathrm{C} / \mathrm{C}, \mathrm{n}(\%)$ & T type, n (\%) & C type, n (\%) \\
\hline \multicolumn{7}{|c|}{ Uygur population } \\
\hline PD & 175 & $5(2.9)$ & $0(0.0)$ & $170(97.1)$ & $10(2.9)$ & $340(97.1)$ \\
\hline Control & 163 & $2(1.2)$ & $0(0.0)$ & $161(98.8)$ & $4(1.2)$ & $322(98.8)$ \\
\hline \multicolumn{7}{|c|}{ Han population } \\
\hline PD & 189 & $0(0.0)$ & $0(0.0)$ & $189(100.0)$ & $0(0.0)$ & $378(100.0)$ \\
\hline Control & 183 & $3(1.6)$ & $0(0.0)$ & $180(98.4)$ & $6(1.6)$ & $360(98.4)$ \\
\hline
\end{tabular}

PD, Parkinson's disease; PINK1, PTEN-induced putative kinase 1.

Table III. Allele and genotype frequencies of the PINK1 gene T313M polymorphism in patients with PD from Uygur and Han populations.

\begin{tabular}{|c|c|c|c|c|c|c|}
\hline \multirow[b]{2}{*}{ Groups } & \multirow[b]{2}{*}{ No. of cases } & \multicolumn{3}{|c|}{ Genotype frequency } & \multicolumn{2}{|c|}{ Allele frequency } \\
\hline & & $\mathrm{T} / \mathrm{T}, \mathrm{n}(\%)$ & $\mathrm{C} / \mathrm{T}, \mathrm{n}(\%)$ & $\mathrm{C} / \mathrm{C}, \mathrm{n}(\%)$ & T type, n (\%) & C type, n (\%) \\
\hline Uygur with PD & 175 & $5(2.9)$ & $0(0.0)$ & $170(97.1)$ & $10(2.9)$ & $340(97.1)$ \\
\hline Han with PD & 189 & $0(0.0)$ & $0(0.0)$ & $189(100.0)$ & $0(0.0)$ & $378(100.0)$ \\
\hline
\end{tabular}

PD, Parkinson's disease; PINK1, PTEN-induced putative kinase 1.

difference from those in the control group $(\mathrm{P}>0.05)$, whereas allele frequencies were observed to be significantly different between the PD and control groups $\left(\chi^{2}=6.247, \mathrm{P}<0.05\right.$; Table II $)$.

When the Uygur and Han patients with PD were compared, the genotype and allele frequencies were observed to differ significantly between the two groups $\left(\chi^{2}=5.475, \chi^{2}=10.950\right.$, $\mathrm{P}<0.05$; Table III). When the study subjects were grouped according to age, ( $\leq 50$ years and $>50$ years), the T313M polymorphisms in the PD group compared with the control group showed no significant difference ( $\mathrm{P}>0.05$; Table IV). Furthermore, when the study subjects were grouped according to gender, T313M polymorphisms in the PD group compared with the control group also showed no significant difference $(\mathrm{P}>0.05$, Table V).

\section{Discussion}

Mutations in the PINK1 gene on chromosome 1p36 have been reported in $\sim 5 \%$ of patients with autosomal recessive PD (13). PINK1 mutations have been reported in patients with autosomal recessive early-onset PD (AREP) in Italy $(14,15)$. The frequency of PINK1 mutations in patients with AREP is between 2.9 and $29 \%$, with the mutation frequency varying greatly depending on ethnicity (16-20). In patients with sporadic early-onset PD (EOP), the pathogenic role of PINK1 mutation is particularly important $(13,21)$. The mutation frequency range is wide. PINK1 gene mutation has not been observed in patients with sporadic PD in the USA (22). Furthermore, among a Chinese population in Taiwan, only one 
Table IV. Association between age and allele and genotype frequencies of the PINK1 gene T313M polymorphism in patients with PD and healthy individuals

\begin{tabular}{|c|c|c|c|c|c|c|c|}
\hline \multirow[b]{2}{*}{ Age } & \multirow[b]{2}{*}{ Group } & \multirow[b]{2}{*}{ No. of cases } & \multicolumn{3}{|c|}{ Genotype frequency } & \multicolumn{2}{|c|}{ Allele frequency } \\
\hline & & & $\mathrm{T} / \mathrm{T}, \mathrm{n}(\%)$ & $\mathrm{C} / \mathrm{T}, \mathrm{n}(\%)$ & $\mathrm{C} / \mathrm{C}, \mathrm{n}(\%)$ & T type, $\mathrm{n}(\%)$ & C type, n (\%) \\
\hline \multirow[t]{2}{*}{$\leq 50$ years } & PD & 80 & $1(1.3)$ & $0(0.0)$ & 79 (98.8) & $2(1.3)$ & 158 (98.8) \\
\hline & Control & 74 & $0(0.0)$ & $0(0.0)$ & $74(100.0)$ & $0(0.0)$ & $148(100.0)$ \\
\hline \multirow[t]{2}{*}{$>50$ years } & PD & 284 & $4(1.4)$ & $0(0.0)$ & $280(98.6)$ & $8(1.4)$ & $560(98.6)$ \\
\hline & Control & 285 & $5(1.8)$ & $0(0.0)$ & $280(98.2)$ & $10(1.8)$ & $560(98.2)$ \\
\hline
\end{tabular}

PD, Parkinson's disease; PINK1, PTEN-induced putative kinase 1.

Table V. Association between gender and allele and genotype frequencies of the PINK1 gene T313M polymorphism in patients with PD and healthy individuals.

\begin{tabular}{|c|c|c|c|c|c|c|c|}
\hline \multirow[b]{2}{*}{ Gender } & \multirow[b]{2}{*}{ Group } & \multirow[b]{2}{*}{ No. of cases } & \multicolumn{3}{|c|}{ Genotype frequency } & \multicolumn{2}{|c|}{ Allele frequency } \\
\hline & & & $\mathrm{T} / \mathrm{T}, \mathrm{n}(\%)$ & $\mathrm{C} / \mathrm{T}, \mathrm{n}(\%)$ & $\mathrm{C} / \mathrm{C}, \mathrm{n}(\%)$ & T type, n (\%) & C type, n (\%) \\
\hline \multirow[t]{2}{*}{ Male } & PD & 206 & $3(1.5)$ & $0(0.0)$ & $203(98.5)$ & $6(1.5)$ & $406(98.5)$ \\
\hline & Control & 193 & $1(0.5)$ & $0(0.0)$ & $192(99.5)$ & $2(0.5)$ & $384(99.5)$ \\
\hline \multirow[t]{2}{*}{ Female } & $\mathrm{PD}$ & 158 & $2(1.3)$ & $0(0.0)$ & $156(98.7)$ & $4(1.3)$ & $312(98.7)$ \\
\hline & Control & 153 & $4(2.6)$ & $0(0.0)$ & 149 (97.4) & $8(2.6)$ & 298 (97.4) \\
\hline
\end{tabular}

PD, Parkinson's disease; PINK1, PTEN-induced putative kinase 1.

heterozygous PINK1 gene mutation was found in 73 patients with sporadic EOP (22). In Italy, patients with sporadic EOP have been reported to have relatively high mutation rates (14). Klein et al (15) observed that PINK1 gene mutations in patients with sporadic EOP were similar to those in the parkin gene (15). At present, few reports on minority PD genes are available, particularly concerning the PINK1 T313M mutation in populations in Xinjiang, China.

The present study showed that genotype frequencies and allele frequency distributions were not significantly different between patients with sporadic PD and healthy control individuals in the total study population. However, in patients with PD, the distribution of T313M polymorphisms was significantly different between patients from the Uygur and Han populations, and all were homozygous mutants. These findings suggest that differences in gene polymorphisms may exist between patients with PD from Uygur and Han populations. These findings are inconsistent with those of Guo et al (23) and Zhang et al (24), who identified that in 120 patients with sporadic PD, as well as in patients with pedigree mutations, mutations may not only exist in patients with familial PD, but also those with sporadic PD in the Han population. However, the sample size should be further expanded and uneven sampling may be associated with the results observed. In the present study, in the Uygur populations, the allele frequencies of the T313M polymorphism in the PD group were not found to be significantly different from those in the control group. However, in the Han population, the allele frequencies were observed to be significantly different in the PD group compared with the control group. These findings differ from those obtained in other regions of mainland China (25). When grouped according to age and gender, the PD and control groups showed no statistically significant difference. Further expansion of the sample size of the patients with early-onset $\mathrm{PD}$ is necessary to verify these findings. It has previously been reported that homozygous or compound heterozygous PINK1 mutations are more common in patients with AREP and single heterozygous mutations are found in patients with sporadic EOP $(19,26,27)$. The present study showed that in the Xinjiang area, T313M polymorphism of the PINK1 gene in the PD and control groups was a homozygous mutation. Significant differences were found between the Uygur and Han populations; the $\mathrm{T}$ allele frequency was $2.9 \%$ in the Ugyur patients with $\mathrm{PD}$, whereas the $\mathrm{T}$ allele was absent from the Han patients with PD, suggesting that T313M gene polymorphism was related to nationality. The Uygur population may be expected to have an increased prevalence of PD due to the incidence of PINK1 mutations. However, no significant difference was observed between the PD group and the control group, and the frequency of the type $\mathrm{T}$ allele $(1.4 \%)$ was not found to increase PD prevalence. In the present study, no significant difference was observed in the allele and genotype frequencies of the PINK1 gene T313M polymorphism in patients aged $\leq 50$ years compared with those aged $>50$ years. This finding suggests that T313M may not be a predisposing factor of early-onset PD. 
The present study identified that differences in T313M polymorphisms exist between the Uygur and Han populations. The PINK1 gene may be associated with genetic susceptibility to PD, particularly in the Han population, which may be associated with the particular area of Xinjiang, living environment and genetic background. Furthermore, sampling may be not uniform. Further investigations, including a larger sample size, are required to validate these results.

\section{References}

1. Koziorowski D, Hoffman-Zacharska D, Sławek J, et al: Incidence of mutations in the PARK2, PINK1, PARK7 genes in Polish early-onset Parkinson disease patients. Neurol Neurochir Pol 47: 319-324, 2013.

2. Vincow ES, Merrihew G, Thomas RE, et al: The PINK1-Parkin pathway promotes both mitophagy and selective respiratory chain turnover in vivo. Proc Natl Acad Sci USA 110: 6400-6405, 2013.

3. Billia F, Hauck L, Grothe D, et al: Parkinson-susceptibility gene DJ-1/PARK7 protects the murine heart from oxidative damage in vivo. Proc Natl Acad Sci USA 110: 6085-6090, 2013.

4. Valente EM, Abou-Sleiman PM, Caputo V, et al: Hereditary early-onset Parkinson's disease caused by mutations in PINK1. Science 304: 1158-1160, 2004.

5. Valente EM, Bentivoglio AR, Dixon PH, et al: Localization of a novel locus for autosomal recessive early-onset parkinsonism, PARK6, on human chromosome 1p35-p36. Am J Hum Genet 68: 895-900, 2001

6. Rogaeva E, Johnson J, Lang AE, et al: Analysis of the PINK1 gene in a large cohort of cases with Parkinson disease. Arch Neurol 61: 1898-1904, 2004.

7. Weng YH, Chou YH, Wu WS, et al: PINK1 mutation in Taiwanese early-onset parkinsonism : clinical, genetic, and dopamine transporter studies. J Neurol 254: 1347-1355, 2007.

8. Ephraty L, Porat O, Israeli D, et al: Neuropsychiatric and cognitive features in autosomal-recessive early parkinsonism due to PINK1 mutations. Mov Disord 22: 566-569, 2007.

9. Kumazawa R, Tomiyama H, Li Y, et al: Mutation analysis of the PINK1 gene in 391 patients with Parkinson disease. Arch Neurol 65: 802-808, 2008.

10. Deng H, Le W, Shahed J, et al: Mutation analysis of the parkin and PINK1 genes in American Caucasian early-onset Parkinson disease families. Neurosci Lett 430: 18-22, 2008.

11. Zhang BR, Hu ZX, Yin XZ, et al: Mutation analysis of parkin and PINK1 genes in early-onset Parkinson's disease in China. Neurosci Lett 477: 19-22, 2010.

12. Hughes AJ, Daniel SE, Kilford L and Lees AJ: Accuracy of clinical diagnosis of idiopathic Parkinson's disease: a clinicopathological study of 100 cases. J Neurol Neurosurg Psychiatry 55: 181-184, 1992.
13. Hilker R, Pilatus U, Eggers C, et al: The bioenergetic status relates to dopamine neuron loss in familial PD with PINK1 mutations. PLoS One 7: e51308, 2012.

14. Scornaienchi V, Civitelli D, De Marco EV, et al: Mutation analysis of the PINK1 gene in Southern Italian patients with early- and late-onset parkinsonism. Parkinsonism Relat Disord 18: 651-653, 2012.

15. Klein C, Djarmati A, Hedrich K, et al: PINK1, Parkin, and DJ-1 mutations in Italian patients with early-onset parkinsonism. Eur J Hum Genet 13: 1086-1093, 2005.

16. Moura KC, Campos Junior M, de Rosso AL, et al: Genetic analysis of PARK2 and PINK1 genes in Brazilian patients with early-onset Parkinson's disease. Dis Markers 35: 181-185, 2013.

17. Lohmann E, Dursun B, Lesage S, et al: Genetic bases and phenotypes of autosomal recessive Parkinson disease in a Turkish population. Eur J Neurol 19: 769-775, 2012.

18. Yonova-Doing E, Atadzhanov M, Quadri M, et al: Analysis of LRRK2, SNCA, Parkin, PINK1, and DJ-1 in Zambian patients with Parkinson's disease. Parkinsonism Relat Disord 18: 567-571, 2012.

19. Zhang X, Zhang H, Liao B, Guo J, Xia K and Tang B: Mutation analysis of PINK1 gene in patients with early-onset Parkinsonism. Zhong Nan Da Xue Xue Bao Yi Xue Ban 36: 490-497, 2011.

20. Keyser RJ, Lesage S, Brice A, Carr J and Bardien S: Assessing the prevalence of PINK1 genetic variants in South African patients diagnosed with early- and late-onset Parkinson's disease. Biochem Biophys Res Commun 398: 125-129, 2010.

21. Kondapalli C, Kazlauskaite A, Zhang N, et al: PINK1 is activated by mitochondrial membrane potential depolarization and stimulates Parkin E3 ligase activity by phosphorylating serine 65. Open Biol 2: 120080, 2012.

22. Fung HC, Chen CM, Hardy J, et al: Analysis of the PINK1 gene in a cohort of patients with sporadic early-onset parkinsonism in Taiwan. Neurosci Lett 394: 33-36, 2006.

23. Guo JF, Xiao B, Liao B, et al: Mutation analysis of Parkin, PINK1, DJ-1 and ATP13A2 genes in Chinese patients with autosomal recessive early-onset Parkinsonism. Mov Disord 23: 2074-2079, 2008.

24. Zhang YH, Tang BS, Guo JF, et al: Mutation analysis of PINK1 gene in Chinese patients with autosomal recessive early-onset parkinsonism type 6. Zhonghua Yi Xue Za Zhi 85: 1538-1541, 2005 (In Chinese).

25. Guo JF, Zhang XW, Nie LL, et al: Mutation analysis of Parkin, PINK1 and DJ-1 genes in Chinese patients with sporadic early onset parkinsonism. J Neurol 257: 1170-1175, 2010.

26. Bonifati V, Rohé CF, Breedveld GJ, et al: Early-onset parkinsonism associated with PINK1 mutations: frequency, genotypes, and phenotypes. Neurology 65: 87-95, 2005.

27. Moura KC, Junior MC, de Rosso AL, et al: Exon dosage variations in Brazilian patients with Parkinson's disease: analysis of SNCA, PARKIN, PINK1 and DJ-1 genes. Dis Markers 32: 173-178, 2012. 